\title{
Effect of onion (Allium cepa L.) as an antibiotic growth promoter substitution on performance, immune responses and serum biochemical parameters in broiler chicks
}

\author{
Majid Goodarzi ${ }^{1^{*}}$, Nasir Landy ${ }^{2}$, Shahram Nanekarani $^{1}$ \\ ${ }^{1}$ Department of Animal Science, Borujerd Branch, Islamic Azad University, Lorestan, Iran; \\ *Corresponding Author: majidgoudarzi117@gmail.com \\ ${ }^{2}$ Young Researchers Club of Islamic Azad University, Khorasgan Branch, Isfahan, Iran
}

Received 6 May 2013; revised 6 June 2013; accepted 1 July 2013

Copyright (C) 2013 Majid Goodarzi et al. This is an open access article distributed under the Creative Commons Attribution License, which permits unrestricted use, distribution, and reproduction in any medium, provided the original work is properly cited.

\section{ABSTRACT}

This experiment was conducted to evaluate the effect of onion (Allium cepa L.) as an antibiotic growth promoter substitute on growth performance, immune responses and serum biochemistry in broilers. A total of 192 one-d-old as hatched broiler chicks (Ross 308) were weighed and randomly allocated to four treatment groups, each with 4 replicate pens of 12 chicks. The dietary treatments consisted of the basal diet (control), antibiotic (15 $\mathrm{mg}$ Virginiamycin $/ \mathrm{kg})$, and control +10 or $30 \mathrm{~g}$ fresh onion bulb/kg diet. Body weights of broilers were determined at $d 1$, 21 and 42, feed intake was determined at the same periods, and feed conversion ratio was calculated accordingly. At 14th and 21st days blood samples were taken for measuring antibody titers against NDV and at 42nd day for biochemical analysis. At d 42, two birds per replicate were slaughtered for determination of lymphoid organ weights. Dietary supplementation of $30 \mathrm{~g} / \mathrm{kg}$ onion increased final body weight of broilers at 42nd $d$ of age compared to the other treatments $(P<0.05)$. Birds fed $30 \mathrm{~g}$ onion $/ \mathrm{kg}$ in the diet had the highest feed intake than other treatments at different growth periods $(P<0.05)$. Dietary treatments failed to induce any significant effect on antibody titers against NDV, although the weight of lymphoid organs was significantly $(P<0.05)$ higher for birds fed diets supplemented with $30 \mathrm{~g} / \mathrm{kg}$ Onion. Broilers receiving $30 \mathrm{~g} / \mathrm{kg}$ onion had a significantly higher HDL and lower triglyceride concentrations com- pared to control groups $(P<0.05)$. Feeding 30 $\mathrm{g} / \mathrm{kg}$ onion resulted in a marked reduction in the concentration of the glucose compared to control groups $(P<0.05)$. The results suggested that dietary inclusion of $30 \mathrm{~g} / \mathrm{kg}$ onion can be applied as alternatives to in-feed antibiotics for broiler diets.

Keywords: Allium cepa; Onion; Broiler Chickens; Immune Response; Serum Biochemical Parameters

\section{INTRODUCTION}

Subtherapeutic feeding of antibiotics has historically been a practice in some sectors of the commercial broiler industry to promote growth performance and protect flock health $[1,2]$. However, the use of dietary antibiotics has resulted in controversial problems such as development of antibiotic resistant bacteria and drug residue in the final products [3] which can be harmful to consumers. Thus, the use of antibiotics as a growth promoter is no longer acceptable and it is forbidden in European Union countries. As a result new alternatives are being introduced to livestock producers, among which phytogenic and herbal products have been given considerable attention as possible in-feed antibiotics substitutions. In recent years, the use of phytogenic compounds has gained momentum for their potential role as natural alternatives to antibiotic growth promoters in animal nutriation $[4,5]$.

The genus Allium includes about 550 species. A few of these are important as food plants and as drugs in folk medicine, notably onion (Allium cepa L.) and garlic (Allium sativum L.). Onion is a bulbous plant widely cultivated in almost every country of the world with leading 
production in China, India and United States [6]. Onion bulbs possess numerous organic sulphur compounds including Trans-S-(1-propenyl) cysteine sulfoxide, S-methylcysteine sulfoxide, Spropylcycteine sulfoxides and cycloallicin, flavinoids, phenolic acids, sterols including cholesterol, stigma sterol, b-sitosterol, saponins, sugars and a trace of volatile oil compounds mainly of sulphur compounds [7]. Most of the plant parts contain compounds with proven antibacterial, antiviral, antiparasitic, antifungal properties and have antihypertensive, hypoglycemic, antithrombotic, antihyperlipidemic, anti inflammatory and antioxidant activity [8].

Aji et al. [9] observed the beneficial influence of onion bulbs on growth performance of broiler chickens. Sebastian et al. [10] reported that administration of onion extract in rabbits significantly reduced serum, liver and aorta triglycerides and serum and liver proteins. The aim of this work was to evaluate the effects of the inclusion of two levels of fresh onion bulbs on broiler responses regarding growth, immune responses and serum biochemistry.

\section{MATERIALS AND METHODS}

\subsection{Animals and Dietary Treatments}

One hundred ninety two, 1-d-old broiler chickens (mean initial weight: $35.5 \pm 1$ g) of mixed sex (Ross-308) were weighed and randomly assigned to each of the 4 treatment groups, each with 4 replicate pens of 12 chicks. The dietary treatments included the basal diet (control), control $+15 \mathrm{mg}$ Virginiamycin/kg, or control +10 or 30 $\mathrm{g}$ fresh onions (Allium cepa) bulb/kg diet. Table 1 lists the basal diet formulated according to the nutrient requirements of broilers provided by National Research Council [11]. The birds were fed a starter diet from 0 to $21 \mathrm{~d}$ and grower diet from 22 to $42 \mathrm{~d}$. All the dietary treatments were added to the basal diets at the expense of sand. Chicks were raised on floor pens $(120 \times 120 \times 80$ $\mathrm{cm})$ for $6 \mathrm{wk}$ and had free access to feed and water throughout the entire experimental period. The lighting program consisted of a period of $23 \mathrm{~h}$ light and $1 \mathrm{~h}$ of darkness. The ambient temperature in experimental house was maintained at $32^{\circ} \mathrm{C}$ during the first week and gradually decreased by $3^{\circ} \mathrm{C}$ in the second and third weeks, and finally fixed at $22^{\circ} \mathrm{C}$ thereafter.

\subsection{Performance}

Body weights of broilers were determined at d 1, 21, and 42 of age. Feed intake and weight gain were recorded in different periods and feed conversion ratio (FCR) was calculated. Mortality was recorded as it occurred and was used to adjust the total number of birds to determine the total feed intake per bird and FCR.
Table 1. The ingredient and calculated composition of basal starter and grower diets.

\begin{tabular}{|c|c|c|}
\hline Item & Starter & Grower \\
\hline \multicolumn{3}{|l|}{ Ingredient, g/kg } \\
\hline Corn & 505.1 & 524.6 \\
\hline Soybean meal & 385 & 350 \\
\hline Soybean oil & 35.8 & 59 \\
\hline Mono calcium phosphate & 14.2 & 10 \\
\hline $\mathrm{CaCO}_{3}$ & 17.3 & 16.7 \\
\hline $\mathrm{NaCl}$ & 3.1 & 2.1 \\
\hline $\mathrm{NaHcO}_{3}$ & 2 & 1.6 \\
\hline Trace mineral premix ${ }^{1}$ & 2.5 & 2.5 \\
\hline Vitamin premix ${ }^{2}$ & 2.5 & 2.5 \\
\hline DL-Methionine & 2.5 & 1 \\
\hline L-Lysine & - & - \\
\hline Sand & 30 & 30 \\
\hline \multicolumn{3}{|l|}{ Calculated composition } \\
\hline Metabolizable energy (kcal/kg) & 2,900 & 3,100 \\
\hline Crude protein (g/kg) & 215 & 200 \\
\hline Calcium (g/kg) & 10 & 9 \\
\hline Available phosphorus (g/kg) & 4.5 & 3.5 \\
\hline Methionine + cysteine (g/kg) & 9 & 7.2 \\
\hline Lysine (g/kg) & 11.8 & 10.9 \\
\hline
\end{tabular}

${ }^{1}$ Provided the following per kg of diet: Mg, $56 \mathrm{mg}$; Fe, $20 \mathrm{mg}$; Cu, $10 \mathrm{mg}$; Zn, $50 \mathrm{mg}$; Co, $125 \mathrm{mg}$; I, $0.8 \mathrm{mg}$. ${ }^{2}$ Provided the following per kg of diet: vitamin A, 10,000 IU; vitamin $\mathrm{D}_{3}$, $2000 \mathrm{IU}$; vitamin E, 5 IU; vitamin $\mathrm{K}, 2$ $\mathrm{mg}$; riboflavin, $4.20 \mathrm{mg}$; vitamin $\mathrm{B}_{12}, 0.01 \mathrm{mg}$; pantothenic acid, $5 \mathrm{mg}$; nicotinic acid, $20 \mathrm{mg}$; folic acid, $0.5 \mathrm{mg}$; choline, $3 \mathrm{mg}$.

$$
\text { FCR }=\text { Feed intake/weight gain }
$$

\subsection{Immune Parameters}

The commercially available oil-adjuvant injectable emulsion against Newcastle Disease virus (NDV) and Avian Influenza virus (AIV) were used (H9N2 subtype) for vaccinating broiler chicks, and they were injected subcutaneously with $0.2 \mathrm{~mL}$ per chick at $9 \mathrm{~d}$ of age. At 14 and 21 days of age two birds per replicate were randomly chosen and blood samples were collected from the brachial vein and centrifuged at $2000 \times \mathrm{g}$ for $15 \mathrm{~min}$ to obtain serum (SIGMA 4 - 15 Lab Centrifuge, Germany). Antibody titers against NDV were measured using Hemagglutination Inhibition Test according to the method of Thayer and Beard [12].

At $42 \mathrm{~d}$ of age, three birds per replicate were randomly 
chosen, based on the average weight of the group and slaughtered through cutting carotid arteries and partial slicing of the neck by a manual neck cutter; bursa and spleen were collected, weighed and calculated as a percentage of live body weight.

\subsection{Serum Biochemistry}

After $12 \mathrm{~h}$ of fasting, blood samples were collected in non-heparinised tubes at day 42 of age from 8 birds in each treatment by puncturing the brachial vein and the blood was centrifuged at $2000 \times \mathrm{g}$ for $15 \mathrm{~min}$ to obtain serum (SIGMA 4 - 15 Lab Centrifuge, Germany). Individual serum samples were analyzed for glucose, total cholesterol, high-density lipoprotein (HDL) and lowdensity lipoprotein (LDL) cholesterol and triglyceride (Pars-Azmoon Co., Tehran).

\subsection{Statistical Analysis}

The obtained data were subjected to analysis of variance procedures appropriate for a completely randomized design using the General Linear Model procedures of SAS Institute (2008). Means were compared using Duncan multiple test. Statements of statistical significance are based on $P<0.05$.

\section{RESULTS}

\subsection{Performance Parameters}

The impact of dietary treatments on growth performance indices from 1 to 42 day of age is presented in Table 2 . At $21 \mathrm{~d}$ of age BW of chicks did not differ $(P>$
0.05) between the dietary treatments, although BW of broiler supplemented with $30 \mathrm{~g}$ onion/kg was higher than other groups. At the end of the trial (d 42), birds supplemented with the $30 \mathrm{~g}$ onion/kg had a greater BW compared with other groups $(P<0.05)$. The average daily feed intake (from d 1 to 21$)$ was increased $(P<0.05)$ for bird supplemented with $30 \mathrm{~g}$ onion/ $\mathrm{kg}$ of diet. The average daily feed intake (ADFI) during grower and the entire experimental period was higher for broilers supplemented with $30 \mathrm{~g}$ onion/kg compared with control birds and birds supplemented with antibiotic $(P<0.05)$. Broilers receiving 10 or $30 \mathrm{~g}$ onion/ kg had a lower feed conversion ratio (FCR) compared to broilers receiving antibiotic during the starter period $(P<0.05)$, but FCR of broilers in other periods was not affected. No differences because of treatment effects were observed on mortality.

\subsection{Immunity}

The effects of treatments on immune related parameters are shown in Tables $\mathbf{3}$ and $\mathbf{4}$. The additives used in the current study failed to induce any significant impact on antibody titers against NDV at 14 and 21 days of age $(P>0.05)$. The weight of lymphoid organs was signed ( $P$ $<0.05$ ) higher for birds fed diets supplemented with 30 g/kg Onion.

\subsection{Serum Biochemistry}

Table 5 summarizes the impact of treatments on serum constituents at day 42 of age. Treatments did not induce any significant effect on the serum concentration of total cholesterol and LDL-cholesterol. Broilers receiving 30

Table 2. Effect of experimental diets on performance indices of broilers at different ages.

\begin{tabular}{|c|c|c|c|c|c|}
\hline \multirow[t]{2}{*}{ Performance parameters } & \multicolumn{5}{|c|}{ Dietary treatments } \\
\hline & Control & Virginiamycin & 10 g/kg Onion & 30 g/kg Onion & SEM $^{1}$ \\
\hline \multicolumn{6}{|c|}{ Daily Feed Intake (g per bird/day) } \\
\hline $0-21 d$ & $31.4^{\mathrm{ab}}$ & $31.4^{\mathrm{ab}}$ & $29.4^{\mathrm{b}}$ & $32.6^{\mathrm{a}}$ & 0.33 \\
\hline $21-42 d$ & $122.5^{\mathrm{b}}$ & $124.5^{\mathrm{b}}$ & $128.9^{\mathrm{ab}}$ & $133.5^{\mathrm{a}}$ & 3.29 \\
\hline $0-42 d$ & $77.0^{\mathrm{b}}$ & $78.0^{\mathrm{b}}$ & $79.2^{\mathrm{ab}}$ & $83.0^{\mathrm{a}}$ & 1.96 \\
\hline \multicolumn{6}{|l|}{ Feed Conversation Ratio (g/g) } \\
\hline $0-21 d$ & $1.53^{\mathrm{ab}}$ & $1.56^{\mathrm{a}}$ & $1.51^{\mathrm{b}}$ & $1.51^{\mathrm{b}}$ & 0.005 \\
\hline $21-42 d$ & 1.87 & 1.89 & 1.92 & 1.89 & 0.014 \\
\hline \multicolumn{6}{|l|}{ Body Weight (g) } \\
\hline $21 d$ & 465.8 & 463.8 & 447.1 & 477.5 & 16.79 \\
\hline $42 \mathrm{~d}$ & $1838.3^{b}$ & $1845.2^{\mathrm{b}}$ & $1859.2^{\mathrm{b}}$ & $1955.1^{\mathrm{a}}$ & 14.84 \\
\hline
\end{tabular}

Values in the same row not sharing a common superscript differ significantly $(P<0.05)$. ${ }^{1}$ Standard error of mean. 
Table 3. Effect of experimental diets on lymphoid organs at 42nd day.

\begin{tabular}{cccccc}
\hline \multirow{2}{*}{ Lymphoid organs } & \multicolumn{5}{c}{ Dietary treatments } \\
\cline { 2 - 6 } & Control & Antibiotic & $10 \mathrm{~g} / \mathrm{kg}$ Onion & $30 \mathrm{~g} / \mathrm{kg}^{2}$ Onion & SEM $^{1}$ \\
\hline Bursa $^{\mathrm{a}}$ & $0.137^{\mathrm{d}}$ & $0.165^{\mathrm{b}}$ & $0.149^{\text {cd }}$ & $0.190^{\mathrm{a}}$ & 0.010 \\
Spleen $^{\mathrm{a}}$ & $0.111^{\mathrm{b}}$ & $0.139^{\mathrm{ab}}$ & $0.138^{\mathrm{ab}}$ & $0.148^{\mathrm{a}}$ & 0.005 \\
\hline
\end{tabular}

Values in the same row not sharing a common superscript differ significantly $(P<0.05) .{ }^{\mathrm{a}}$ Percentage of live body weight. ${ }^{1}$ Standard error of mean.

Table 4. Effect of experimental diets on antibody titers against Newcastle Disease Virus at 14th and 21st days.

\begin{tabular}{ccccccc}
\hline & \multicolumn{5}{c}{ Dietary treatments } \\
\cline { 2 - 6 } Antibody titers $(\log )$ & Control & Antibiotic & $10 \mathrm{~g} / \mathrm{kg}$ Onion & $30 \mathrm{~g} / \mathrm{kg}$ Onion & $\mathrm{SEM}^{1}$ \\
\hline 14 days & 0.619 & 0.650 & 0.643 & 0.650 & 0.016 \\
21 days & 0.739 & 0.775 & 0.775 & 0.775 & 0.019 \\
\hline
\end{tabular}

${ }^{1}$ Standard error of mean.

Table 5. Effect of experimental diets on serum biochemical parameters of broilers at day 42 .

\begin{tabular}{|c|c|c|c|c|c|}
\hline \multirow{2}{*}{ Serum biochemistry } & \multicolumn{5}{|c|}{ Dietary treatments } \\
\hline & Control & Antibiotic & 10 g/kg Onion & 30 g/kg Onion & $\mathrm{SEM}^{1}$ \\
\hline Triglyceride $^{\mathrm{a}}$ & $120.67^{\mathrm{a}}$ & $111.25^{\mathrm{ab}}$ & $104.25^{\mathrm{ab}}$ & $95.75^{\mathrm{b}}$ & 7.59 \\
\hline Total cholesterol $^{\mathrm{a}}$ & 146.29 & 153.14 & 130.60 & 134.00 & 11.83 \\
\hline LDL-cholesterol $^{\mathrm{a}}$ & 36.75 & 32.75 & 30.50 & 41.75 & 6.77 \\
\hline HDL-cholesterol $^{\mathrm{a}}$ & $77.75^{\mathrm{b}}$ & $94.25^{\mathrm{a}}$ & $86.25^{\mathrm{ab}}$ & $88.75^{\mathrm{a}}$ & 2.89 \\
\hline Glucose $^{\mathrm{a}}$ & $93.75^{\mathrm{a}}$ & $81.75^{\mathrm{ab}}$ & $75.00^{\mathrm{ab}}$ & $59.00^{\mathrm{b}}$ & 7.37 \\
\hline
\end{tabular}

Values in the same row not sharing a common superscript differ significantly $(P<0.05) .{ }^{1}$ Standard error of mean. ${ }^{\mathrm{a}}(\mathrm{mg} / 100 \mathrm{~mL})$.

g/kg onion had a significantly higher HDL and lower triglyceride concentrations compared to control groups $(P<0.05)$. Feeding $30 \mathrm{~g} / \mathrm{kg}$ onion resulted in a marked reduction in the concentration of the glucose compared to control groups $(P<0.05)$.

\section{DISCUSSION}

\subsection{Performance}

Dietary supplementation of $30 \mathrm{~g} / \mathrm{kg}$ onion increased body weight and feed intake of broilers at different growth periods. Also, feeding $30 \mathrm{~g} / \mathrm{kg}$ onion resulted in a marked reduction in the concentration of the glucose. Onion containing sulfur organic compounds including S-Methylcysteine sulfoxide (SMCS) and S-allylcysteine suiloxide (SACS) is related to decreasing of blood lipid, liver protein and glucose. Hypoglycemia stimulates a nerve center for intake whereas hyperglycemia stimulates the center for satiety. Shurlock and Forbes [13] observed reductions in feed intake after they infused glucose into the hepatic portal vein of fasted chickens at physiological rates, whereas no effect was observed when glucose was infused into the jugular vein. Onion stimulated growth by increasing the inflow of glucose into tissues, thyroid like activity. The results of the present experiment are consistent with Al-homidan [14]. Similar to our results Aji et al. [9] reported an enhancement in BW, FCR and ADFI of broilers offered diets containing fresh onion bulbs in comparison with broilers fed basal diet. In this trial the positive impact of the onion on the feed utilization was observed at starter period, but the improved FCR obtained in broilers supplemented with $30 \mathrm{~g}$ onion/kg was not reflected at grower period probably due to the facts that older birds' nutrient requirements decrease with age and also they have a better developed digestive tracts and organs [4].

\subsection{Immunity}

With respect to a higher weight of lymphoid organs recorded in chicks fed onion diets, it is concluded that the active components of onion which have antibacterial, antiviral, antifungal, anti inflammatory and antioxidant activities [8] induce positive effects on these organs. These results are in agreement with those obtained by 
Ibrahiem et al. [15] who reported that bursa weights were magnified by feeding onion to broiler muscovy ducks. Onions have a mode of action which is similar to antibiotics. Yamamoto and Glick [16] reported that the synthesis of immunoglobulins was higher in chicken with larger Bursa. Dafwang et al. [17] reported that the effects of onion and garlic on immunoglobulins were similar to antibiotics. But in the present trial that antibody titers measured against NDV, neither positive nor negative effect was affected. Since antimicrobial agents started to be used as growth promoters, researchers $[18,19]$ working with broilers and swine respectively understood that the presence of an important health challenge in the field was essential to reveal the significant effects of these products. This was while the current trial was conducted in optimum conditions and no external challenges or stresses were impelled to the broilers.

\subsection{Serum Biochemistry}

Broilers receiving $30 \mathrm{~g} / \mathrm{kg}$ onion had a significantly higher HDL and lower triglyceride concentrations compared to control groups. Suresh and Srinivasan [20] found that $3 \%$ onion powder reduced blood lipids, lipid peroxides and cholesterol. Al-homidan [14] and Sebastian et al. [10] also observed the reduced serum cholesterol in their experiments by using of onion. In contrast to the foreign experiments, Sklan et al. [21] did not observe any effect of onion on hepatic cholesterol. The effects of onion have been ascribed to its sulfur containing principles which oxidize thiol compounds either present free or combined with a protein and NADPH which are necessary for lipid synthesis [10].

In conclusion, the results suggested that the dietary inclusion of $30 \mathrm{~g} / \mathrm{kg}$ onion can be applied as an alternative to in-feed antibiotics for broiler diets.

\section{ACKNOWLEDGEMENTS}

This study was supported by the Islamic Azad University, Borujerd Branch, Lorestan, Iran.

\section{REFERENCES}

[1] Landy, N., Ghalamkari, G.H., Toghyani, M., et al. (2011) The effects of Echinacea purpurea L. (Purple Coneflower) as an antibiotic growth promoter substitution on performance, carcass characteristics and humoral immune response in broiler chickens. Journal of Medicinal Plants Research, 5, 2332-2338.

[2] Landy, N. Ghalamkari, G.H. and Toghyani, M. (2011) Performance, carcass characteristics and immunity in broiler chicks fed dietary Neem (Melia azadirachta) as alternative for an antibiotic growth promoter. Livestock Science, 142, 305-309. doi:10.1016/j.livsci.2011.08.017

[3] Burgat, V. (1999) Residues of drugs of veterinary use in food. La Revue du Praticien, 41, 985-990.

[4] Toghyani, M., Toghyani, M., Gheisari, A.A., et al. (2011) Evaluation of cinnamon and garlic as antibiotic growth promoter substitutions on performance, immune responses, serum biochemical and haematological parameters in broiler chicks. Livestock Science, 138, 167-173. doi:10.1016/j.livsci.2010.12.018

[5] Landy, N., Ghalamkari, G.H. and Toghyani, M. (2012) Evaluation of St John's Wort (Hypericum perforatum L.) as an antibiotic growth promoter substitution on performance, carcass characteristics, some of the immune responses, and serum biochemical parameters of broiler chicks. Journal of Medicinal Plants Research, 6, 510-515. doi:10.5897/JMPR11.1371

[6] Ebesunun, M.O., Popoola, O.O., Agbedana, E.O., et al. (2007) The effect of garlic on plasma lipids and lipoproteins in rats fed on high cholesterol enriched diet. Biokemistri, 19, 53-58.

[7] Melvin, J.M., Jayochitra, J. and Vijayapriaya, M. (2009) Antimicrobial activity of some common spices against certain human pathogens. Journal of Medicinal Plants Research, 3, 1134-1136.

[8] Lampe, J.W. (1999) Health effects of vegetables and fruits: Assessing mechanisms of action in human experimental studies. The American Journal of Clinical Nutrition, 70, 475-490.

[9] Aji, S.B., Ignatius, K., Y. Ado, A. Abdulkarim, et al. (2011) Feeding Onion (Allium cepa) and Garlic (Allium sativum) on some performance characteristics of broiler chickens. Research Journal of Poultry Sciences, 4, 22-27. doi:10.3923/rjpscience.2011.22.27

[10] Sebastian, K., Zacharias, N., Philip, B., et al. (1979) The hypolipidemic effect of onion (Allium cepa Linn) in sucrose fed rabbits. Indian Journal of Physiology and Pharmacology, 23, 27-30.

[11] National Research Council (1994) Nutrient requirements of poultry. 9th Edition, NAS-NRC, Washington DC.

[12] Thayer, S.G. and Beard, C.W. (1998) Serologic procedures. In: Swayne, D.E., Ed., A Laboratory Manual for the Isolation and Identification of Avian Pathogens, 4th Edition, American Association of Avian Pathologists, Philadelphia, 256-258.

[13] Shurlock, T.G.H. and Forbes, J.M. (1981) Evidence for hepatic glucostatic regulation of food intake in the domestic chicken and its interaction with gastro-intestinal control. British Poultry Science, 22, 333-346. doi:10.1080/00071688108447893

[14] AL-Homidan, A.A. (2005) Efficacy of using different sources and levels of Allium cepa, Allium sativum and Zingiber officinale on broiler chicks performance. Saudi Journal of Biological Sciences, 12, 96-102.

[15] Ibrahiem A.I., Talib, A.E., Fathi, F.M., et al. (2004) Effect of onion and/or garlic as feed additives on growth performance and immunity in broiler muscovy ducks. First Scientific Conference of Faculty of Veterinary Medicine, Benhar, 1-4 September 2004.

[16] Yamamoto, Y. and Glick, B. (1998) A comparison of the immune response between two lines of chickens selected 
for differences in the weight of the bursa of Fabricius. Poultry Science, 61, 2129-2132. doi:10.3382/ps.0612129

[17] Dafwang, L.M.E., Sunde, M.L. and Bird, H.R. (1985) Bursal, intestinal and spleen weight and antibody response of chicks feed substance therapeutic levels of dietary. Poultry Science, 64, 634-639. doi:10.3382/ps.0640634

[18] Coates, M.E., Davies, M.K. and Kon, S.K. (1952) The effect of antibiotics on the intestine of the chick. British Journal of Nutrition, 9, 110-119. doi:10.1079/BJN19550016

[19] Whitehair, C.K. and Thompson, C.M. (1956) Observa- tions in raising "disease-free" swine. Journal of the American Veterinary Medical Association, 128, 94-98.

[20] Suresh Babu, P. and Srinivasan, K. (1997) Influence of dietary capaicin and onion on the metabolic abnormalities associated with streptozotocin induced diabetes mellitus. Molecular and Cellular Biochemistry, 175, 49-57. doi:10.1023/A:1006881027166

[21] Sklan, D., Bernera, Y.N. and Rabinowitch, H.D. (1992) The effect of dietary onion and garlic on hepatic lipid concentrations and activity of antioxidative enzymes in chicks. The Journal of Nutritional Biochemistry, 3, 322325. doi:10.1016/0955-2863(92)90022-B

\section{Supplement}

FCR = Feed conversion ratio;

NDV = Newcastle Disease virus;

AIV = Avian Influenza virus;

HDL = High-density lipoprotein;
LDL = Low-density lipoprotein;

BW = Body Weight;

ADFI = Average daily feed intake;

$\mathrm{NADPH}=$ Nicotinamide adenine dinucleotide phosphate;

SEM $=$ Standard error of mean . 